\title{
UM ESTUDO SIGNIFICATIVO DE EXPRESSÕES ALGÉBRICAS E EQUAÇÕES
}

\author{
Amanda Alves de Lima \\ Universidade Federal de Campina Grande-UFCG \\ amandalimasjp@gmail.com \\ Rosinângela Cavalcanti da Silva \\ Professora na Universidade Federal de Campina Grande-UFCG \\ professorarosinangela@gmail.com
}

\begin{abstract}
RESUMO
Este trabalho tem o intuito de relatar experiências vivenciadas, na disciplina de Estágio, do curso de Licenciatura em Matemática da Universidade Federal de Campina Grande, desenvolvidas nas aulas de Matemática de uma Escola Municipal de Ensino Fundamental, com a turma do $8^{\circ}$ ano. O projeto desenvolvido teve como objetivo mostrar que a Matemática deve estar relacionada com questões práticas da vida dos alunos, dando significado ao conteúdo, com a finalidade de levar os alunos a construírem seus conhecimentos de forma prática e diferenciada, construindo assim, seus conhecimentos de forma concreta. O projeto foi dotado de propostas significativas, as quais visaram facilitar a compreensão e aprendizagem dos alunos. Abordando o estudo de Expressões Algébricas e Equações, de maneira diferenciada, mostrando que a aplicação desses conteúdos está inserida no cotidiano do aluno.
\end{abstract}

PALAVRAS-CHAVE: Ensino Diferenciado; Matemática; Projeto.

\section{INTRODUÇÃO}

O presente trabalho tem como objetivo, abordar a importância da utilização de métodos diferenciados para um ensino eficaz, quebrando barreiras existentes no pensamento dos alunos, que a Matemática é algo assustador, que é impossível compreendê-la.

Os alunos do ensino fundamental passam por diversas fases que necessitam de mudanças e adaptações, e dessa forma novas capacidades precisam ser desenvolvidas. Para isto, são necessárias aulas contextualizadas, inovadoras, que realmente chamem atenção, pois aquelas aulas mecânicas não funcionam mais. Para que o aluno preste atenção, o professor precisa trazer algo novo para a sala de aula, que motive os alunos. 
O bom professor não é aquele que ensina muitos conteúdos, e sim o que consegue fazer com que todos os alunos realmente aprendam aquilo que the é ensinado. O professor precisa produzir um espaço adequado para o processo de ensino aprendizagem, buscando recursos e tecnologias para elaborar suas aulas, explorando sua criatividade e planejamento, investindo de todas as formas para elaborar uma aula que gere aprendizagem, preparando os alunos para as mudanças contínuas da realidade, formando cidadãos críticos e responsáveis na sociedade.

Aulas diferenciadas chamam mais atenção dos alunos, recursos tecnológicos, jogos e situações problema, são boas opções para despertar o interesse dos alunos, pois é notório, que eles não estão aprendendo, através do método de ensino utilizado atualmente pelos professores. Se o método adotado não traz resultados, então não adianta ficar repetindo, explicando várias vezes da mesma forma. O professor precisa e deve mudar essa realidade, usando ao máximo sua criatividade na hora de planejar as aulas, para que estas despertem a vontade de aprender e descobrir o mundo.

Os alunos do $8^{\circ}$ ano são pré-adolescentes, mas já tem uma opinião formada sobre as coisas e gostam de expor essa opinião na maioria das vezes, possuem uma curiosidade diferente, estão descobrindo o que querem da vida e não são mais tão frágeis. É essencial despertar nos educandos o desejo de aprender, mostrar que a Matemática não é tão complicada assim, pelo contrário, é uma disciplina que está sempre presente no nosso dia a dia.

Planejar uma aula diferenciada e inovadora é essencial para desenvolver todas essas habilidades e competências, o professor precisa ir além, e para isso, é preciso planejar, é necessário investir em algo novo, que chame a atenção do educando e o leve a pensar. Elaborar uma aula com situações problema é fantástico, desenvolvendo no aluno seu raciocino lógico, promovendo uma aprendizagem significativa. Situações problema é uma das estratégias de mais eficácia para a aprendizagem dos alunos, no qual, possibilita vivenciar determinadas situações em seu dia a dia, quebrando barreiras e dificuldades para compreensão do conteúdo, fazendo perceberem que a Matemática se aplica ao seu cotidiano, criando uma conexão com o conteúdo abordado e seu cotidiano, quebrando assim, os rótulos que a Matemática não serve para nada. 
A Resolução de Problemas é um método eficaz para desenvolver o raciocínio e para motivar os alunos para o estudo da Matemática. O processo ensino e aprendizagem pode ser desenvolvido através de desafios, problemas interessantes que possam ser explorados e não apenas resolvidos. (LUPINACCI e BOTIN, 2004, p.1).

$\mathrm{Na}$ compreensão da Matemática, as situações problema são fundamentais, possibilitando o aluno posicionar diante de questionamentos, desenvolvendo seu raciocínio lógico e não apenas o uso de regras soltas, mas sim, aprender realmente com algo significativo.

É possível por meio da resolução de problemas desenvolver no aluno iniciativa, espírito explorador, criatividade, independência e a habilidade de elaborar um raciocínio lógico e fazer uso inteligente e eficaz dos recursos disponíveis, para que ele possa propor boas soluções às questões que surgem em seu dia-a-dia, na escola ou fora dela. (DANTE, 1991, p.25).

O método de resolução de problemas é de extrema importância para o processo de ensino aprendizagem da Matemática, criando no educando a competência para desenvolver o pensamento Matemático, não se prendendo apenas a exercícios repetitivos e desinteressantes, que não acrescenta nada na vida do aluno, sendo o principal motivo do insucesso escolar.

Jogos educativos é uma ferramenta muito eficaz no processo de ensino aprendizagem, chamando atenção dos alunos, fazendo com que aprendam de forma prática, mudando a rotina da sala de aula, promovendo uma melhor participação de toda a turma. Na maioria das vezes, os alunos não conseguem se expor durante a aula, por vergonha, ou por medo de falar algo no qual os colegas fiquem rindo disso. Já o jogo promove a participação de todos, sem medo de errar, conseguindo se expressar melhor, gerando dessa forma, uma melhor aprendizagem.

É muito mais fácil e eficiente aprender por meio de jogos, e isto é válidos para todas as idades, desde o maternal até a fase adulta. O jogo em si possui componentes do cotidiano e o envolvimento desperta o interesse do aprendiz, que se torna sujeito ativo do processo. (LOPES, 2000, p.23).

É dever do educador matemático buscar alternativas para motivar a aprendizagem dos educandos, desenvolvendo o raciocínio lógico, concentração, curiosidade, e o uso de jogos é um recurso muito importante para a construção do conhecimento, permitindo uma melhor compreensão do conteúdo abordado, através da interação com os colegas, permitindo assim, 
aprender de maneira prática e divertida, mudando dessa forma a rotina da sala de aula, despertando o interesse dos alunos.

Vale ressaltar que o jogo é um recurso no qual, objetivos devem ser traçados, visando alcançar todas as metas, não se deve permitir que o aluno participe do jogo de qualquer forma, ele não pode achar que o jogo é apenas uma brincadeira, ele deve entender que é uma ferramenta que irá facilitar a compreensão do conteúdo trabalhado em sala de aula, então é necessário que o aluno realmente participe, e consiga atingir os objetivos esperados.

Outro motivo para a introdução de jogos nas aulas de matemática é a possibilidade de diminuir bloqueios apresentados por muitos de nossos alunos que temem a Matemática e sentem-se incapacitados para aprendê-la. Dentro da situação de jogo, onde é impossível uma atitude passiva e a motivação é grande, notamos que, ao mesmo tempo em que estes alunos falam Matemática, apresentam também um melhor desempenho e atitudes mais positivas frente a seus processos de aprendizagem. (BORIN, 1996, p.9).

O jogo é uma ótima ferramenta, na qual os alunos absorvem e compartilham conhecimentos, de forma interativa e divertida, desenvolvendo também o espírito de competição. Isso mostra como é possível ensinar Matemática de maneira prazerosa, tornando os alunos protagonistas do seu próprio aprendizado. Sendo assim, uma aula bem planejada faz toda a diferença, o professor deve buscar de todas as formas recursos que possibilitem uma aula diferenciada, despertando assim, o interesse dos alunos.

Dessa forma, o uso de metodologias diferenciadas é essencial, vale ressaltar, que um bom professor, precisa ficar sempre se atualizando, buscando, inovando cada dia mais, de acordo com o avanço das tecnologias, pois o aluno do presente fica atento somente a algo novo, e é isso que o professor precisa trazer para a sua sala de aula, conseguindo então, despertar sua curiosidade, facilitando dessa maneira, a aprendizagem.

\section{DESENVOLVIMENTO}

Ensinar bem não significa apenas repassar os conteúdos, ensinar é muito mais que isso, é levar o aluno a pensar, questionar e criticar. $\mathrm{O}$ professor precisa produzir o conhecimento em sintonia com o aluno, deve mostrar que os conhecimentos ensinados serão 
aplicados cotidianamente, despertando a curiosidade nos alunos, a vontade de aprender cada vez mais, trabalhando as competências de cada um.

Ensinar não é oferecer aos educandos um conhecimento pronto e acabado, e sim auxiliá-los, procurando a melhor maneira para chegar até esses conhecimentos, é criar condições de desenvolvimento. Nesse sentido, o professor tem um papel fundamental no sucesso da aprendizagem e o modo como atua em sala de aula é decisivo para o desempenho dos alunos.

É comum ouvir que, para a maioria dos alunos, a Matemática é a grande vilã entre todas as disciplinas, muitos declaram que não gostam de Matemática porque é muito complicada, e que não conseguem entender nada do que o professor explica. O principal motivo para a Matemática ser tão detestada é que os alunos não veem significado no conteúdo abordado em sala de aula, acham algo sem importância e constrangedor.

O projeto de ensino foi uma atividade proposta na disciplina de Estágio, onde foi acompanhada a escrita do projeto a partir das discussões sobre metodologias de ensino, desenvolvidas na disciplina Prática de Ensino de Matemática no Ensino Fundamental, a qual norteia o professor em formação, para que ele possa construir sua própria prática docente. $\mathrm{O}$ Estágio foi desenvolvido durante quatro semanas, iniciando no dia 18 de abril de 2016 e finalizando no dia 13 de maio de 2016, numa Escola Municipal de Ensino Fundamental com a turma do $8^{\circ}$ ano. Através deste estágio foi possível ter um contato direto com a realidade dos alunos e das escolas públicas.

O projeto: "O Mundo da Matemática" dividiu-se em duas etapas. Na primeira etapa, foi abordado o conteúdo Expressões Algébricas, foi dado início no assunto, contando a história da Álgebra, em seguida foi feita uma dinâmica para introduzir o conteúdo, sendo trabalhado, em seguida, situações problema e depois, foi realizada uma atividade em dupla, finalizando o conteúdo com uma gincana, dividindo a turma em dois grupos, buscando promover a interação entre toda a turma. Nessa primeira etapa, foi observado, que os alunos estavam desmotivados, sem nenhuma força de vontade para aprender, com o bloqueio de nunca tentar, porque considerava difícil, achando sempre impossível, se achando incapaz. $\mathrm{O}$ primeiro passo foi planejar, sempre levando algo novo para sala de aula, preparando aulas significativas, dinâmicas, que chamassem a atenção dos alunos, que promovesse uma interação de toda a turma, que despertasse o interesse, promovendo assim, uma aprendizagem 
significativa. Logo no início não foi fácil trabalhar dessa maneira, pois era algo diferente para todos os alunos, eles resistiram um pouco, mas depois, eles prestaram atenção, se interessaram, e falaram que gostaram muito dos métodos adotados, que estudar assim era muito melhor, que conseguiram perceber que Matemática não é tão complicada, tudo depende de como é transmitido o conteúdo.

Na segunda etapa, foi abordado o conteúdo Equações, sendo iniciado dando um contexto histórico, a partir da narração da história das Equações, em seguida, foi realizada uma dinâmica para introduzir o assunto abordado, sendo trabalhado, em seguida, situações problema. Foi trabalhado também o jogo Trilha das Equações, o qual desenvolveu o espírito competitivo nos alunos, para finalizar o conteúdo foi proposta uma atividade individual, como forma de avaliar a aprendizagem do assunto trabalhado. Nessa última etapa, foi constatado, que foi muito mais simples fazer os alunos prestarem atenção, eles interagiram facilmente, se dedicaram bastante, e as aulas foram ainda mais proveitosas, já que todos os alunos estavam atentos a cada momento da aula, gerando assim, uma melhor aprendizagem. Diante disso, foi verificado que, com a execução do projeto, os alunos tiveram um bom desempenho acerca dos conteúdos trabalhados, todo o planejamento foi desenvolvido da melhor forma, gerando assim uma aprendizagem significativa. Toda a expectativa foi alcançada, desenvolvendo todo o estágio com segurança e um ótimo desempenho.

Com o intuito de mostrar que a Matemática está relacionada com questões práticas da vida do aluno, dando significado ao que foi estudado, é que foi proposto o projeto, não apenas como mais um conteúdo a ser estudado, mas como algo que vai muito além da sala de aula, acrescentando algo novo na vida de cada aluno. Com a finalidade de levar os educandos a construírem seus conhecimentos de forma dinâmica e contextualizada, o projeto foi dotado de propostas significativas e inovadoras, fazendo uso da História da Matemática, dinâmicas, situações problema e jogo educativo, no qual facilitaram a compreensão e aprendizagem dos alunos.

\section{CONSIDERAÇÕES FINAIS}

O ensino da Matemática abrange muitas dificuldades, muitos alunos veem a Matemática como algo mais complicado do que é na realidade, geram um bloqueio antes 
mesmo de tentar. É preciso buscar alternativas para mudar isso, tendo conhecimento de que o ensino da Matemática no contexto atual está direcionado para uma perspectiva tradicional.

Como professores, temos a missão de mostrar que essa disciplina é extremamente necessária para entendermos tudo o que acontece ao nosso redor. É preciso que seja feita uma mudança na metodologia dos professores de Matemática, é necessário procurar alternativas que busquem modificar algumas práticas educacionais, tendo conhecimento de que o ensino da Matemática no contexto atual está voltado somente para uma perspectiva tradicional. Dessa forma, cabe a ele sempre buscar novos conhecimentos que tornem sua metodologia adequada para as necessidades educacionais referidas na atualidade. Mostrando que a Matemática não se resume unicamente a fórmulas, essa realidade de decorar fórmulas, tem que ser mudada, os alunos necessitam de aulas que construam algo em suas vidas. A escola do presente e do futuro exige inovações, aquela aula em que o aluno apenas decora fórmulas não deve existir, o aluno tem que analisar e interpretar situações problemas que se relacionem com sua realidade.

O projeto de ensino proporcionou trabalhar de forma contextualizada, dinâmica e diferenciada. Com a aplicação do projeto, foi visto que o desempenho dos alunos diante dos conteúdos trabalhados desenvolveu-se da melhor forma, facilitando o processo de ensino aprendizagem. Possibilitando um melhor desempenho na sala de aula, com aulas contextualizadas, dinâmicas e inovadoras, onde foram ferramentas fundamentais na regência, com o objetivo de atingir uma aprendizagem significativa. Com a aplicação do projeto foi visto que, o desempenho dos alunos diante dos conteúdos trabalhados desenvolveu-se da melhor forma, facilitando o processo de ensino aprendizagem. Dessa maneira, o projeto atingiu todas as expectativas e estabeleceu-se como uma das melhores maneiras de organizar as aulas, dando suporte para desenvolver o estágio com total desempenho. Dessa forma, o estágio foi de extrema importância para o aprendizado, enquanto licenciando em Matemática, ampliou a visão no que diz respeito à realidade do contexto escolar, o que irá contribuir positivamente para a futura prática docente. Foi muito satisfatório ouvir dos alunos que diante das aulas planejadas, eles conseguiram aprender todos os conteúdos lecionados, pois eles estavam acostumados somente com aulas tradicionais, e diante dessas aulas inovadoras, foi construído o conhecimento, despertado o interesse pela disciplina, e perceberam que a Matemática pode sim, ser legal, e que não se resume unicamente a fórmulas. 


\title{
A SIGNIFICANT STUDY OF ALGERIA EXPRESSIONS AND EQUATIONS
}

\begin{abstract}
This work intends to report experiences in the Mathematics course of the Federal University of Campina Grande, developed in the Mathematics classes of a Municipal School of Elementary Education, with the group of the 8th grade. The aim of the project was to show that Mathematics should be related to practical issues in students' lives, giving meaning to the content, in order to lead the students to build their knowledge in a practical and differentiated way, thus building their knowledge of form Concrete. The project was endowed with significant proposals, which aimed to facilitate students' understanding and learning. Approaching the study of Algebraic Expressions and Equations, in a differentiated way, showing that the application of these contents is inserted in the daily life of the student.
\end{abstract}

KEYWORDS: Special Education; Mathematics; Project.

\section{SIGNIFICANT STUDY OF ALGERIA EXPRESSIONS AND EQUACIONES RESUMEN}

Este trabajo tiene el propósito de relatar experiencias vivenciadas, en la disciplina de Etapa, del curso de Licenciatura en Matemáticas de la Universidad Federal de Campina Grande, desarrolladas en las clases de Matemáticas de una Escuela Municipal de Enseñanza Fundamental, con la clase del $8^{\circ}$ año. El proyecto desarrollado tuvo como objetivo mostrar que la Matemática debe estar relacionada con cuestiones prácticas de la vida de los alumnos, dando significado al contenido, con la finalidad de llevar a los alumnos a construir sus conocimientos de forma práctica y diferenciada, construyendo así, sus conocimientos de forma Concretamente. El proyecto fue dotado de propuestas significativas, las cuales pretendían facilitar la comprensión y el aprendizaje de los alumnos. Abordando el estudio de Expresiones Algébricas y Ecuaciones, de manera diferenciada, mostrando que la aplicación de esos contenidos está inserta en el cotidiano del alumno.

PALABRAS CLAVES: Enseñanza Diferenciada; Matemáticas; Diseño.

\section{REFERÊNCIAS BIBLIOGRÁFICAS}

BORIN, J. Jogos e resolução de problemas: uma estratégia para as aulas de matemática. São Paulo: IME-USP; 1996.

DANTE, L. R. Didática da resolução de problemas de matemática. 2. ed. São Paulo: Ática, 1991.

LOPES, Maria da Glória. Jogos na Educação: criar, fazer, jogar. $3^{\text {a }}$ edição. São Paulo: Cortez, 2000. 
LUPINACCI, M. L. V. e BOTIN, M. L. M. Resolução de problemas no ensino de matemática. Anais do VIII Encontro Nacional de Educação Matemática, Recife, 2004.

VYGOTSKY, L. A Formação Social da Mente. São Paulo: Martins Fontes, 1998. 